\title{
Proses Pembentukan Gasket berlapis dengan Metode Elemen Hingga
}

\author{
I Made Gatot Karohika ${ }^{1)^{\star}}$, I Nyoman Gde Antara ${ }^{2)}$ \\ ${ }^{1,2)}$ Jurusan Teknik Mesin Universitas Udayana, Kampus Bukit Jimbaran Bali \\ naskah msauk 09/08/2018; diterima 20/10/2018; terbit 29/10/2018 \\ doi: 10.24843/JEM.2018.v11.i02.p06
}

\begin{abstract}
Abstrak
Perkembangan metode elemen hingga memberikan kemudahan bagi para peneliti untuk memprediksi proses dan hasil forming suatu produk sehingga kegagalan bisa dicegah lebih awal dan biaya karena cacat produk bisa dihindari. Pada penelitian ini, proses forming metal gasket three-layer bentuk bergelombang akan di investigasi dengan analisa simulasi yang menggunakan metode elemen hingga. Kesesuaian bentuk produk gasket dengan cetakan mempengaruhi performance gasket tersebut saat proses tightening. Dimensi cetakan gasket menggunakan cetakan gasket 400MPa-mode dengan variasi ketebalan surface layer. Base material menggunakan SUS304 dan surface layer menggunakan ratio modulus elastis 0.1 dan 0.5 . Hasil simulasi menunjukkan bahwa gasket forming tidak memenuhi cetakan dan pada bagian puncak gelombang gasket terjadi lekukan. Besarnya lekukan pada puncak gelombang menurun dengan naiknya ketebalan surface layer.
\end{abstract}

Kata kunci: pembentukan, gasket, metode elemen hingga

\section{Abstract}

The development of finite element methods help the researchers to predict the process and the result of product forming so that failure can be prevented earlier and costs due to product defects can be avoided. In this study, the process of forming metal gaskets of corrugated three-layer forms will be investigated by simulation analysis using finite element method. The suitability of the shape of the gasket product with the mold affects the performance of the gasket during the tightening process. Gasket mold dimensions use 400MPa-mode gasket molds with surface layer thickness variations. Base material using SUS304 and surface layer using Aluminum. The simulation results show that the forming gasket did not fill the mold and at the peak of the gasket convex occurs indentation. The amount of indentation at the convex of the wave decreases with the increase in surface layer thickness.

Keywords: forming, gasket, finite element method

\section{Pendahuluan}

Dalam sistem perpipaan, gasket memainkan peran penting untuk mencegah kebocoran. Gasket disisipkan diantara dua flens yang memiliki ketidaksempurnaan permukaan sehingga sangat efektif dalam mencegah kebocoran. Bahan gasket yang biasa digunakan adalah asbestos karena tahan terhadap bahan kimia dan memiliki rentang suhu yang lebar. Namun, setelah asbestos diketahui mengandung bahan kimia yang berbahaya dan bisa menyebabkan penyakit serius, penggunaannya pun dilarang. Di Jepang, produksi dan penggunaan asbestos telah dilarang sejak 2008 [1], sehingga sangat urgen dicari bahan alternatif pengganti gasket berbahan asbestos. Para peneliti memiliki tantangan untuk mencari bahan alternatif sebagai pengganti asbestos. Bahan baru ini diharapkan memiliki performa yang serupa dengan asbestos. Beberapa peneliti telah mencoba untuk meneliti bahan baru dan beberapa peneliti lain mengembangkan sistem sealing yang baru dengan mengoptimalkan beberapa parameter perancangan untuk meningkatkan sealing performance [1-7]. Belum ada produk ideal yang bisa menggantikan gasket berbahan asbestos sehingga bahan yang berbeda perlu dikembangkan agar sesuai dengan berbagai aplikasinya.

Penelitian untuk gasket berbahan logam dengan bentuk bergelombang terus dilakukan karena diketahui kinerja gasket menurun dengan semakin meningkatkan kekasaran permukaan flens saat kontak [5]. Gasket dengan bahan SUS304 saat kontak dengan permukaan flens dengan kekasaran permukaan tinggi lebar kontaknya menurun dan permukaan kontak yang terdeformasi plastis tidak mampu memenuhi celah-celah mikro permukaan flens yang tidak sempurna tersebut. Pengembangan gasket berlapis tiga telah dilakukan dengan bagian dalam menggunakan SUS304 dan aluminium, tembaga, nickel sebagai lapisan luarnya dengan ketebalan lapisan $0.1 \mathrm{~mm}$ [11]. Namun proses pembentukan yang terjadi tidak dibahas dalam penelitian tersebut. Proses pembentukan yang sempurna sangat mempengaruhi nantinya kinerja gasket saat kotak dengan flens.

Pada penelitian ini pengaruh ratio modulus elastisitas dan variasi ketebalan logam pelapis terhadap hasil proses pembentukan three-layer corrugated metal gasket dianalisa menggunakan metode elemen hingga. Suksesnya proses komersialisasi sebuah produk baru sangat dipengaruhi waktu menuju pasar. Lebih pendeknya product lead time adalah penting bagi industri di dalam menghadapi pasar yang semakin kompetitif. Ini dapat dicapai hanya jika proses pengembangan produk dapat diwujudkan dalam periode waktu yang pendek. Pengembangan gasket logam biasanya terjadi melalui proses desain 
dan tes manufaktur yang memakan waktu. Salah satu usaha pada pengembangan produk adalah memanfaatkan simulasi computer untuk memprediksi kondisi yang diperlukan menggunakan metode lemen hingga. Model komputasi ini memberikan kontribusi yang besar di dalam mengurangi jumlah eksperimen yang secara konvensional digunakan selama tahap desain sehingga bisa memperpendek product lead time dan biaya yang tinggi bisa diminimalkan.

\section{Metode Penelitian}

\subsection{Bahan}

Gasket yang digunakan dalam penelitian ini adalah tipe bergelombang yang disisipkan diantara flens seperti ditunjukkan oleh gambar 1. Ukuran gasket adalah gasket model $400 \mathrm{MPa}$, yang ditunjukkan pada table 1.

Tabel.1 Desain cetakan gasket model 400-MPa

\begin{tabular}{|c|c|}
\hline Faktor & Ukuran $(\mathrm{mm})$ \\
\hline Overhang $(\mathrm{OH})$ & 3 \\
\hline Pitch $1\left(\mathrm{p}_{1}\right)$ & 3.5 \\
\hline Pitch $2\left(\mathrm{p}_{2}\right)$ & 4.5 \\
\hline Pitch 3 $\left(\mathrm{p}_{3}\right)$ & 3.5 \\
\hline Thickness $(\mathrm{Tg})$ & 1.5 \\
\hline Radius $(\mathrm{R})$ & 2.5 \\
\hline Radius $(\mathrm{R} 1)$ & 2.3 \\
\hline Height $(\mathrm{h})$ & 0.3 \\
\hline Height $(\mathrm{h} 1)$ & 0.33 \\
\hline
\end{tabular}

Tabel 2.Properties SUS304

\begin{tabular}{|c|c|}
\hline Properties & Nilai \\
\hline Yield stress (Mpa) & 398,83 \\
\hline Modulus tangen (Mpa) & 1900,53 \\
\hline Modulus elastisitas (E) GPa & 210 \\
\hline Poisson ratio (v) & 0.3 \\
\hline
\end{tabular}

Pada penelitian ini, pertama-tama pelat tiga lapis dibuat menggunakan software CAD Solidwork. Selanjutnya proses meshing dengan hypermesh untuk elemen size $0.02 \mathrm{~mm}$ tipe elemen quadrilateral. Proses forming gasket berlapis tiga dianalisa menggunakan metode simulasi elemen hingga software MSC. Marc dengan asumsi dua dimensi model axis-symmetric dalam arah axial antara upper dan lower dies seperti ditunjukkan gambar 2. [11]. Upper dan lower dies di asumsikan rigidbodies sedangkan gasket deformable bodies. Dies yang digunakan tipe open dies. Flowchart dari langkahlangkah simulasi gasket dengan mempertimbangkan ratio modulus elastisitas dan variasi ketebalan ditunjukkan pada gambar 3. Ikatan antara lapisan pelat gasket diasumsikan kuat karena proses pelapisan dengan metode cladding; sehingga delaminasi antar permukaan dapat diabaikan.

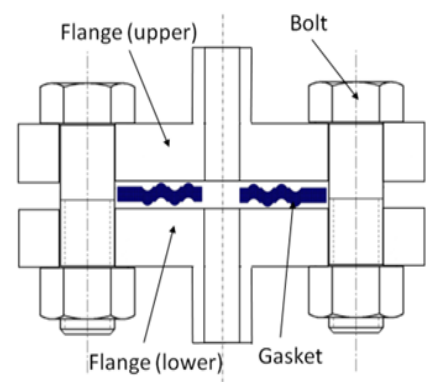

(a)

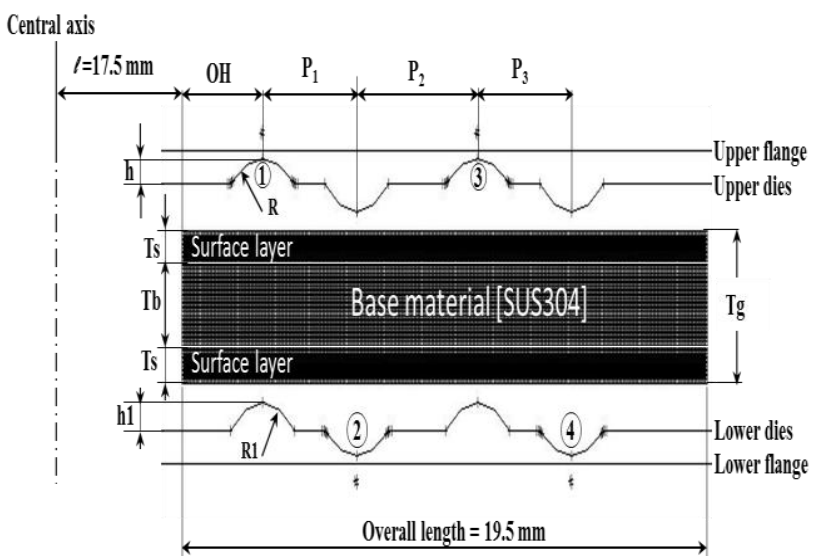

(b)

Gambar 1. (a) Model 2D gasket-flens (b) dimensi dari cetakan gasket

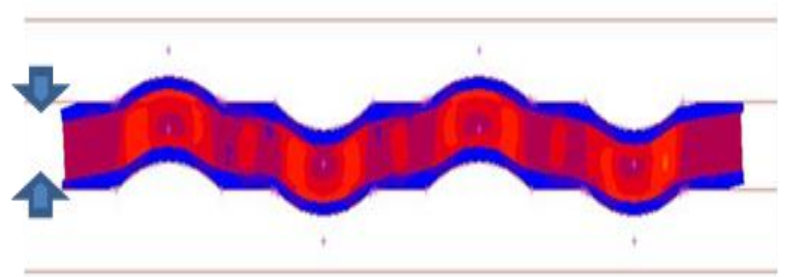

Gambar 2. Simulasi proses Forming untuk model axisymmetric gasket tiga lapis

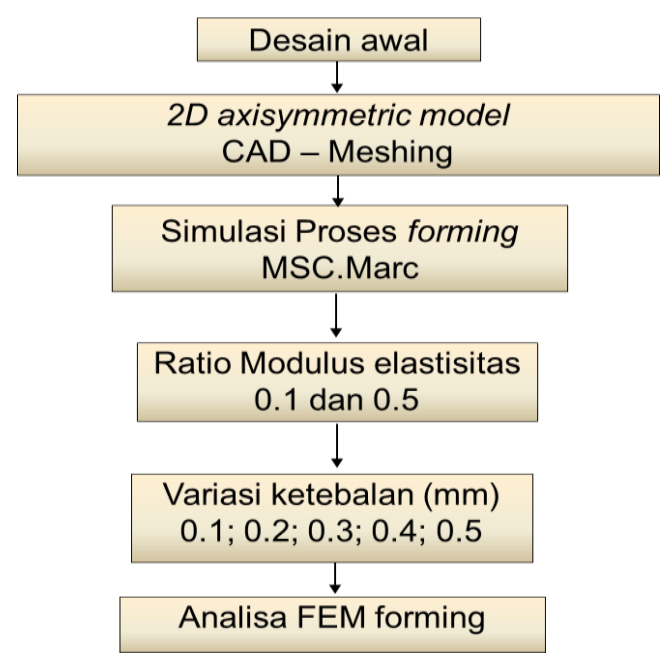

Gambar 3. Flowchart simulasi gasket tiga lapis 
Tebal total gasket model $400 \mathrm{MPa}$ dibuat tetap yaitu (Tg) $1.5 \mathrm{~mm}$ dan overall length $(\mathrm{L})$ adalah 19.5 $\mathrm{mm}$ (Gambar 1).

Properties dari SUS304 sebagai base material mempunyai karakteristik seperti ditunjukkan oleh tabel 2. Ketebalan lapisan permukaan satu bagian (Ts) bervariasi dari $0.1 ; 0,2 ; 0,3 ; 0,4 ; 0,5 \mathrm{~mm}$. Bila ketebalan lapisan (Ts) adalah $0.1 \mathrm{~mm}$, maka ketebalan base material adalah 1,3 mm, demikian seterusnya. Ratio modulus elastisitas (Es/Eb) bervariasi dari 0.1 dan 0.5. Dalam simulasi ini material gasket memenuhi bilinier hardening law

$$
\begin{array}{ll}
\sigma=\mathrm{E} \varepsilon & (\varepsilon<\sigma y / E) \\
\sigma=\sigma y+\mathrm{ET}(\varepsilon-\sigma y / E) & (\varepsilon>\sigma y / E)
\end{array}
$$

Untuk material pelapis dipilih $\sigma y s /$ Es adalah 0.001 , work hardening coefficient ratio adalah 0.01 dan Poisson's ratio adalah 0.3

\section{Hasil dan Pembahasan}

Analisa proses pembentukan gasket 3 lapis difokuskan pada bagian covex gasket, karena kinerja gasket tipe bergelombang untuk mencegah kebocoran sangat dipengaruhi oleh bentuk convexnya. Bentuk convex yang sempurna mempengaruhi lebar kontak dan tegangan kontak yang terjadi pada bagian convex yang mana efektif mencegah kebocoran

\subsection{Pengaruh ratio modulus elastisitas}

Pengaruh ratio modulus elastis pada proses pembentukan gasket model 400 Mpa ditunjukkan oleh gambar 4 dan gambar 5 . Berdasarkan hasil simulasi proses pembentukan menunjukkan cacat produk yang tidak mengisi penuh cetakan terjadi pada semua bagian convex. Cacat cenderung terjadi pada radius bentuk kontak convexnya. Cacat yang tidak mengisi penuh cetakan terjadi baik pada ratio modulus elastisitas 0.1 maupun 0.5 , tetapi ratio 0.1 terdapat cekungan pada puncak convexnya. Hal ini terjadi karena untuk material logam pelapis yang terlalu lunak saat proses pembentukan ketebalan pada radius fillet lebih tipis dibandingkan ketebalan bagian yang lainnya karena lebih mudah terdeformasi plastis. Sehingga nantinya akan mempengaruhi lebar kontak dan tegangan kontak saat kontak dengan flens saat proses pengetatan.
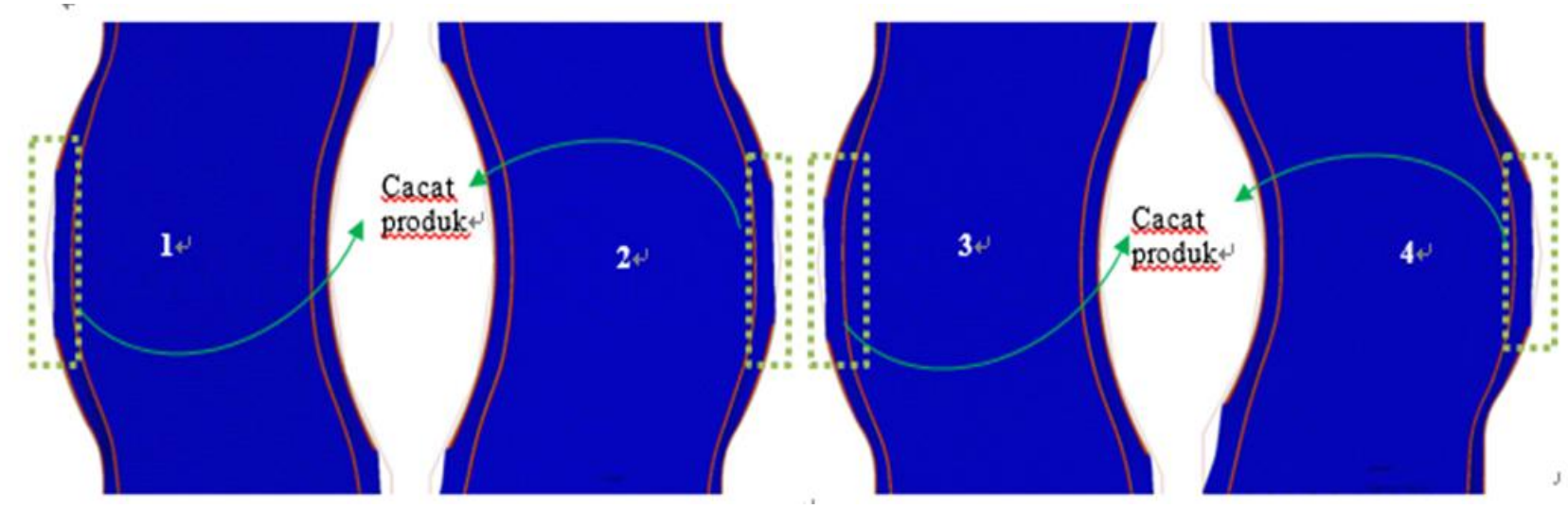

Gambar 4. Proses pembentukan gasket 400-MPa, Es/Eb =0.1.
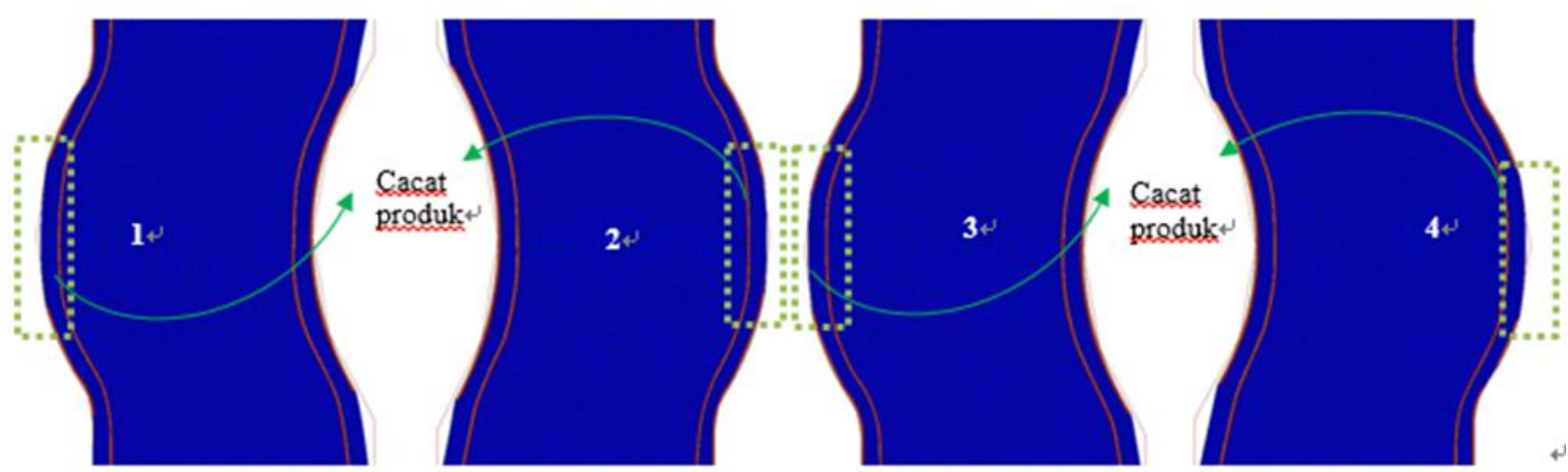

Gambar 5. Proses pembentukan gasket 400-MPa, Es/Eb $=0.5$. 
Table 4. Cacat produk pada proses pembentukan gasket model 400-MPa

\begin{tabular}{|c|c|c|c|c|}
\hline $\begin{array}{c}\text { Ts } \\
(\mathrm{mm})\end{array}$ & Convex1 & Convex2 & Convex3 & Convex4 \\
\hline 0.1 & $\begin{array}{l}\text { Die fill } \\
\text { defect }\end{array}$ & Die fill defect & $\begin{array}{l}\text { Die fill } \\
\text { defect }\end{array}$ & \\
\hline 0.2 & $\begin{array}{l}\text { Die fill } \\
\text { defect }\end{array}$ & $\begin{array}{l}\text { Die fill } \\
\text { defect }\end{array}$ & $\begin{array}{l}\text { Die fill } \\
\text { defect }\end{array}$ & $\begin{array}{l}\text { Die fill } \\
\text { defect }\end{array}$ \\
\hline 0.3 & $\begin{array}{l}\text { Die fill } \\
\text { defect }\end{array}$ & Die fill & $\begin{array}{l}\text { Die fill } \\
\text { defect }\end{array}$ & $\begin{array}{l}\text { Die fill } \\
\text { defect }\end{array}$ \\
\hline 0.4 & $\begin{array}{l}\text { Die fill } \\
\text { defect }\end{array}$ & $\begin{array}{l}\text { Die fill } \\
\text { defect }\end{array}$ & $\begin{array}{l}\text { Die fill } \\
\text { defect }\end{array}$ & $\begin{array}{l}\text { Die fill } \\
\text { defect }\end{array}$ \\
\hline 0.5 & $\begin{array}{l}\text { Die fill } \\
\text { defect }\end{array}$ & $\begin{array}{l}\text { Die fill } \\
\text { defect }\end{array}$ & $\begin{array}{l}\text { Die fill } \\
\text { defect }\end{array}$ & Die fill \\
\hline
\end{tabular}

\subsection{Pengaruh variasi ketebalan}

Untuk menjelaskan pengaruh variasi ketebalan terhadap proses pembentukan kami menggunakan ratio modulus elastisitas 0,1 . Tabel 4 menunjukkan simulasi proses pembentukan untuk gasket model 400 $\mathrm{MPa}$. Di sini juga mengindikasikan adanya cacat produk karena tidak mengisi penuh cetakan. Berdasarkan hasil simulasi menunjukkan cacat tersebut cenderung menurun pada puncak convex dengan naiknya ketebalan logam pelapis permukaan

\section{Simpulan}

Penelitian ini menganalisa pengaruh ratio modulus elastisitas dan variasi ketebalan terhadap hasil proses pembentukan dengan metode simulasi pada gasket tipe bergelombang lapis tiga. Berdasarkan hasil simulasi diperoleh

1. ratio modulus elastisitas 0.5 memilki cacat produk lebih rendah daripada 0.1 .

2. dengan naiknya ketebalan logam lapisan permukaan menghasilkan menurunnya cacat

3. analisis elemen hingga menyediakan referensi yang bermanfaat untuk memprediksi desain gasket baja bergelombang tiga lapis, sehingga kegagalan bisa dicegah lebih awal dan biaya karena cacat produk bisa dihindari

\section{Ucapan Terima Kasih}

Penelitian ini didukung oleh hibah penelitian invensi Udayana PNBP tahun 2018

\section{Daftar Pustaka}

[1] H.A. Saeed, S. Izumi, S. Sakai, S. Haruyama, M. Nagawa, H. Noda, "Development of New Metallic Gasket and its Optimum Design for Leakage Performance", Journal of Solid Mechanics and Material Engineering, Vol. 2, No. 1, 2008, pp. 105114.

[2] S. Haruyama, M.A. Choiron, K. Kaminishi, "A Study of Design Standard and Performance Evaluation on New Metallic Gasket", Proceeding of the $2^{\text {nd }}$ International Symposium on Digital Manufacturing, Wuhan China, 2009, pp. 107-113.

[3] M.A. Choiron, S. Haruyama, K. Kaminishi, "Simulation and Experimentation on the Contact Width of New Metal Gasket for Asbestos Substitution", International Journal of Aerospace and Mechanical Engineering, Vol. 5, No. 4, 2011, pp. 283-287.

[4] D. Nurhadiyanto, M.A. Choiron, S. Haruyama, K. Kaminishi, "Optimization of New 25A-size Metal Gasket Design Based on Contact Width 
Considering Forming and Contact Stress Effect," International Journal of Mechanical and Aerospace Engineering, Vol. 6, 2012, pp. 343-347.

[5] S. Haruyama, D. Nurhadiyanto, M.A. Choiron, K. Kaminishi, "Influence of surface roughness on leakage of new Metal Gasket", International Journal of Pressure Vessels and Piping, 111-112, 2013, pp. 146-154.

[6] S. Haruyama, D. Nurhadiyanto, K. Kaminishi, "Contact Width Analysis of Corrugated Metal Gasket based on Surface Roughness, Advanced Materials Research, Vol. 856, 2014, pp. 92-97.

[7] S. Haruyama, D. Nurhadiyanto, K. Kaminishi., I M.G. Karohika., Mujiono, "Contact Stress and Contact Width Analysis of Corrugated Metal Gasket", Applied Mechanics and Materials, Vols. 799-800, 2015, pp. 765-769.

[8] S. Haruyama, , I M.G. Karohika, A. Sato, D. Nurhadiyanto, K. Kaminishi, , "Development of 25A-Size Three-Layer Metal Gasket by Using FEM Simulation", International Journal of Mechanical Aerospace, Industrial, Mechatronic and Manufacturing Engineering, Vol:10, No:3, 2016, pp.555-561.

[9] MSC Marc 2014, User Manual.

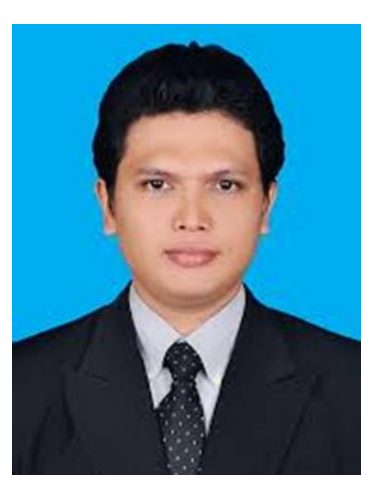

I Made Gatot Karohika menyelesaikan pendidikan S1 Teknik Mesin di Institut Teknologi Sepuluh Nopember Surabaya pada tahun 2001. Pendidikan magister Teknik Mesin diselesaikan di Institut yang sama pada tahun 2008 dengan bidang studi desain sistem mekanikal.

Pada tahun 2014 ia menyelesaikan pendidikan doktoral di Yamaguchi University, Jepang. Saat ini ia bekerja sebagai dosen di Jurusan Teknik Mesin Uinversitas Udayana. Bidang penelitian utama yang digeluti adalah gasket, optimasi desain, finite element analysis. 